impure cast-iron at the present day-and whereby all the impurities would be removed to the surface to form the primal crust. The first of this primal crust would be the most acidic, and the last the most basic; and in the metallic core left, even the oxygen which had been the means of removing all the impurities would itself be undetectable. Thorium is but a higher member of the silicon (carbon) family as uranium is of the uxygen family, and the conditions which remove the lower members should be effective in removing the higher ones also. So, too, it seems only natural that the most acidic rocks-that is, the rocks containing the greatest proportions of silicon and of oxygen-should at the same time be associated with the greatest proportions of thorium and of uranium, which are but the highest members of the silicon and oxygen families.

On the planetesimal hypothesis a similar distribution of the radio-elements can hardly be imagined. To get a metallic core that shall be free from thorium and uranium, we have to imagine the planetesimals undergoing individually the oxidation process which has just been sketched, unless the planetesimals happened to be fragments of a preformed stellar mass. Provided all went well, when these planetesimals were piling themselves together to form the earth, the result would be a metallic core free from thorium and uranium, but surrounded by a crust in which these elements would be uniformly distributed. As the acidic rocks differ only in degree from the basic rocks, it would be impossible for the former to rise up through miles of a mixture of both to form an acidic layer, as happens in the case of a stellar earth. Subsequent aqueous action is relatively negligible in both cases.

It is probably the exigencies of the planetesimal hypothesis that constrain Mr. Holmes to state that there is "clearly a marked antipathy between the radio-rements and native iron, for in all the terrestrial examples which have been examined uranium and thoriuin are barely detectable." As a matter of fact, these elements alloy with iron and nickel, which are the constituents of native iron; and their marked absence is a proof that native iron had undergone an oxidation process at one time in its history, and so had its thorium and uranium removed.

95 Bath Street, Glasgow.

George Craig.

\section{THE INTERNATIONAL UNION FOR SOLAR} RESEARCH.

THE fifth conference of the International Union 1 for Cooperation in Solar Research was held at $B \circ n n$, by invitation of Prof. Kayser, from July $3 \mathrm{I}$ to August 5. The attendance was about IOO, including delegates from nearly every country in Europe, and a large contingent from America. In the absence of Prof. Hale and Dr. Schuster, through sickness, the executive committee was ably represented by Prof. Turner. As on former occasions, the chief business at the general meetings was to receive and discuss the reports of the various committees appointed for the organisation of observations and methods of reduction.

An important part of the work of the union has been that relating to standards of wave-length. At the last meeting, held at Mount Wilson, California, in I9ro, it was believed that a final set of standards was well within sight, but further investigations have revealed unexpected difficulties. It has, in fact, been found by Goos and others that the wave-lengths of many of the iron lines vary slightly with the length of the arc and the portion of the arc observed. Fortunately, most of the lines already adopted as secondary standards, from interferometer determinations, preserve their positions under a variety of circumstances, but they are not sufficient in number. Hence, it has become necessary to attempt the definition of a standard iron arc for determinations of further standards, and for the production of reference spectra to be used in the determination of wavelengths by interpolation. The committee recommended the following specification for the iron arc: (I) Length of arc, $6 \mathrm{~mm}$. (2) For lines of wave-length greater than 4000 , current to be 6 amperes, and for lines of shorter wave-length 4 amperes, or possibly less. (3) Direct current, positive pole above negative, P.D. of 220 volts, electrodes being iron rods of $7 \mathrm{~mm}$. diameter. (4) An axial portion of the arc, at its middle, about $2 \mathrm{~mm}$. in length, to be used as the source of light. Cooperation in the determination of tertiary standards is desired from all who possess concave gratings, plane gratings, or prisms of sufficient dispersion and resolving power, and to this end it is recommended that additional secondary standards be determined with the interformeter, so that the interpolation method may be used with greater exactness.

At the Mount Wilson meeting a committee on the determination of the solar rotation by means of the displacements of lines was formally organised, and a programme of research agreed upon. Each cooperating observer undertook observations, at specified latitudes, in a definite region of the spectrum, in addition to a control region common to all the observers, and lines were to be selected so as to include elements of widely different atomic weights. It now appears that different observers may obtain results differing systematically by as much as Io per cent. from one another, and that serious discrepancies have also been found in the results obtained by different observers from measurements of the same photographs. The committee accordingly recommended that, before proceeding further, investigations of these sources of error should be made by determinations of velocity at the solar equator by as many different methods as possible.

Satisfactory progress in work with the spectroheliograph was reported, but the Committee hoped that additional observatories would install instruments of high dispersion, in order that filaments and alignments in the upper atmosphere might be more completely recorded. As the result of representations made by Prof. Ricco and by the Royal Astronomical Society, the title of the spectroheliograph committee was changed to "Committee on Solar Atmosphere," so as to include and unify all the observations on the solar atmosphere, visual and photographic, except those associated with eclipses. The organisation directed by Prof. Ricco, and other observers of prominences, were thus given the opportunity of closer connection with the union. After some discussion, a subcommittee for visual observations of prominences and related phenomena was appointed, with Prof. 
Ricco as chairman and Father Cortie as secretary. The chief recommendations subsequently made by the sub-committee were that the limiting height of prominences for general statistical purposes should be $30^{\prime \prime}$, and that results should be expressed as profile areas, the conventional "prominence unit" being defined as the area covered by an arc of I degree along the sun's limb and I second of arc of the celestial sphere in height. It is hoped that by this means it may be possible to combine more successfully the records made at different observatories.

From the report presented by the committee on the spectra of sun spots, it appears that spots observed during the recent minimum did not differ appreciably from those observed at maximum, so far as could be determined with instruments of moderate dispersion. It is, however, considered desirable that the systematic visual observations initiated by the committee should be continued at least until r9ı6, so as to include a complete cycle of eleven years. The organisation of photographic investigations of spot spectra has been undertaken, and several observers have already agreed to cooperate in preparing a much-needed catalogue of lines affected in spots, and also in other investigations.

An important outcome of the Mount Wilson meeting was the extension of the scope of the union so as to include astrophysics in general. The committee then appointed to consider the possibility of securing uniformity in the classification of stellar spectra has collected opinions from a great number of workers, and reports that a provisional preference for the Draper classification is nearly unanimous. At the same time, the general feeling is opposed to immediate committal to any system, and an effort will be made to secure the material necessary for the establishment of a classification that can be recommended for permanent and universal adoption.

The formal proceedings were varied by addresses and papers on subjects coming within the scope of the union, and by several interesting social gatherings. The receptions by the municipalities of Bonn and Cologne, and by Prof. and Frau Küstner at the Bonn Observatory, will long remain a pleasant memory to those who were privileged to be present, as will also the excursion on the Rhine generously provided by Prof. Kayser. The success of the conference as a whole was largely due to the admirable arrangements made by Profs. Kayser and Pflüger.

The next conference will be held at Rome in 1916.

\section{A. Fowler.}

\section{THE BRITISH ASSOCIATION.}

\section{Arrangements for the Birmingham Meeting.}

THE meeting, which began on September ro 1 in Birmingham under the presidency of Sir Oliver Lodge, F.R.S., promises to be a large and important one. The number, both of local and of visiting members and associates, amounts at the time of writing to about 2600 .

Among the corresponding and foreign repreNo. 2289 , VOL. 92] sentatives are:-Sir H. Angst (Consul-General, Zurich); Prof. Svante Arrhenius (Stockholm); Prof. Bemmelen (Groningen); Prof. H. Braus (Heidelberg); Prof. Capitan (Paris) ; Prof. Chodat (Geneva); Madame Curie (Paris); Dr. Dollo (Brussels); Prof. Lorentz (Leiden); Prof. Reinke (Kiel); Prof. Keibel (Freiburg); Dr. Versluys (Giessen) ; Dr. Gregory (New York) ; Prof. Pringsheim (Breslau); Prof. Sörensen (Copenhagen); and Prof. R. W. Wood (Baltimore). It is hoped that others may be able to attend the meeting.

A new procedure has been adopted this year with a view to reducing the pressure on the reception room during the first day or two of the meeting. To each intending visitor a "Selection Circular" has been addressed, giving a list of the various functions (addresses, discourses, entertainments, and excursions), which have been arranged, with a request that the functions selected should be indicated on the returned half of the circular. The response to this appeal has been very gratifying, as over fifteen hundred replies have already been received. Nevertheless, the work of the reception room officials has been very heavy.

The usual business meetings were held on Wednesday last. At the general committee a deputation from the Corporation and University of Manchester invited the Association to visit that city

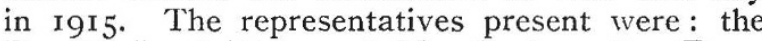
Deputy Lord Mayor of Manchester, the Town Clerk, the Vice-Chancellor, Prof. Horace Lamb, F.R.S., Prof. H. B. Dixon, F.R.S., and Mr. Maxwell Garnett. In the evening the President delivered his long-expected address, the contents of which will now have become known.

On Thursday evening (September $1 \mathrm{I}$ ) the Lord Mayor and Lady Mayoress of Birmingham are holding a reception in the Council House Buildings, in which the new art gallery and natural history museum are lodged. Special loan collections have been deposited in the museum during the association week.

The University Degree Congregation takes place on the afternoon of September Ir, and a fuller account will be given in our next issue. The list of graduands has been limited to a few distinguished men of science from abroad, representative mainly of the chief European nations. The following is the list of recipients of honorary degrees:-Madame Curie (Sorbonne. Paris), Prof. H. A. Lorentz (Leyden), Prof. Keibel (Freiburg), Prof. R. W. Wood (Baltimore), Prof. Svante Arrhenius (Stockholm). In the unavoidable absence of the chancellor, Mr. Joseph Chamberlain, Vice-Chancellor Barling conferred the honorary degree of LL.D. on the graduands, the ceremony in each case being prefaced by a presentation and speech made by the principal ( $\mathrm{Sir}$ Oliver Lodge). After the ceremony the various departments of the New University Buildings were visited.

\section{Entertainments and Excursions.}

With regard to the entertainments: at the garden party given by Messrs. Cadbury Brothers at Bourneville on Friday, September 12, there 